\title{
Interactions between the Bronchial Epithelium and Fibrocytes in the Pathogenesis of Airway Remodeling in Asthma
}

\author{
Alberto Bellini, Matthias Schmidt and Sabrina Mattoli*
}

Avail Biomedical Research Institute, CH-4003 Basel, Switzerland

\begin{abstract}
The histopathologic features of asthma include chronic airway inflammation, increased density of fibroblasts and myofibroblasts in the lamina propria and presence of structural abnormalities of the bronchial wall collectively referred to with the term "airway remodeling”. The newly emerged population of fibroblasts and myofibroblasts contributes to airway remodeling by producing excessive amounts of collagenous and non-collagenous extracellular matrix components in the subepithelial zone and by expanding the mass of contractile cells in the bronchial wall. A substantial proportion of these mesenchymal cells in asthma exhibit the phenotypic and functional characteristic of fibrocytes, which represent a unique population of bone marrow-derived mesenchymal progenitors recruited to tissue sites from the circulation in response to injury or in chronic inflammatory conditions. Recent studies have demonstrated that the asthmatic bronchial epithelium is a major source of fibrocyte chemoattractants and growth factors. This review will focus on the novel observations suggesting that asthmatic epithelial cells may play a key role in the development and progression of airway remodeling by promoting the recruitment and local differentiation of fibrocytes.
\end{abstract}

Keywords: Airway remodeling, Asthma, Bronchial epithelium, Fibrocytes, Myofibroblasts.

\section{AIRWAY REMODELING IN ASTHMA}

Asthma is a clinical syndrome characterized by recurrent episodes of airflow obstruction of variable duration and intensity, which may be triggered by viral infections and exposure to allergens or other environmental stimuli in predisposed individuals [1]. Chronic airway inflammation and remodeling of the normal architecture of the bronchi are histopathologic features that underlie the clinical manifestations of the disease [2]. The remodeling process involves the composition and organization of several cellular, biochemical and molecular components of the bronchial wall [3]. The main structural changes include alterations of the proliferation and apoptotic activity of the epithelium, goblet cell hyperplasia and hypertrophy, thickening of the lamina reticularis (also known as reticular basement membrane), formation of new vessels, and increased smooth muscle mass [2-8] (Fig. 1). The thickening of the lamina reticularis reflects excessive deposition of collagenous and non-collagenous extracellular matrix (ECM) molecules beneath the epithelial basement membrane, particularly collagen types I (COL1), III (COL3) and V (COL5), tenascin, fibronectin, hyaluronan and proteoglycans such as versican, perlecan, lumican and biglycan [9-11]. The development of this subepithelial fibrotic process is an early event in asthma [12], especially in difficult-to-treat disease [13], and the deposition of collagens can extend beyond the lamina reticularis to involve the entire inner wall of the bronchi in severe asthma $[2,14]$. The progression of this structural change may contribute to cause

*Address correspondence to this author at the Avail Biomedical Research Institute, P. O. Box 110, CH-4003 Basel, Switzerland;

Fax: +41 61544 7374; E-mail: smattoli@avail-research.com irreversible airflow obstruction [15-19] and a better understanding of its pathogenesis would allow the development of therapies for the prevention of the progressive loss of lung function in patients whose disease is incompletely responsive to currently available therapeutic options [3].

It is widely recognized that the thickening of the lamina reticularis in asthma may be caused by the excessive release of ECM molecules from a population of subepithelial fibroblast-like cells, which undergo local proliferation and differentiate into myofibroblast-like cells expressing $\alpha$-smooth muscle actin ( $\alpha$-SMA), under the effects of profibrotic factors produced by the dysfunctional asthmatic epithelium and inflammatory cells such as the eosinophils [20-24]. In patients with allergen-exacerbated asthma, every allergen exposure can induce a further increase in the density of fibroblast- and myofibroblast-like cells in the subepithelial zone within 24 hours [25]. The expansion of this population of mesenchymal cells continues for at least 7 days and is associated with an enhanced deposition of ECM components such as COL3 and tenascin in the lamina reticularis. The remodeling process persists for days after the resolution of the allergen-induced increase in the inflammatory infiltrate of the bronchial mucosa [25]. The density of fibroblast- and myofibroblast-like cells is particularly elevated in the bronchial mucosa of patients with the most severe forms of chronically persistent asthma, irrespective of the atopic status, suggesting that a lack of asthma control with frequent disease exacerbations may result in a dramatic progression of the fibrotic process [3]. The accumulation of myofibroblastlike cells in the bronchial mucosa of asthmatic individuals also increases the mass of contractile cells in the bronchial wall and may contribute to enhance the abnormal constrictive activity of the asthmatic bronchial tubes, especially in 


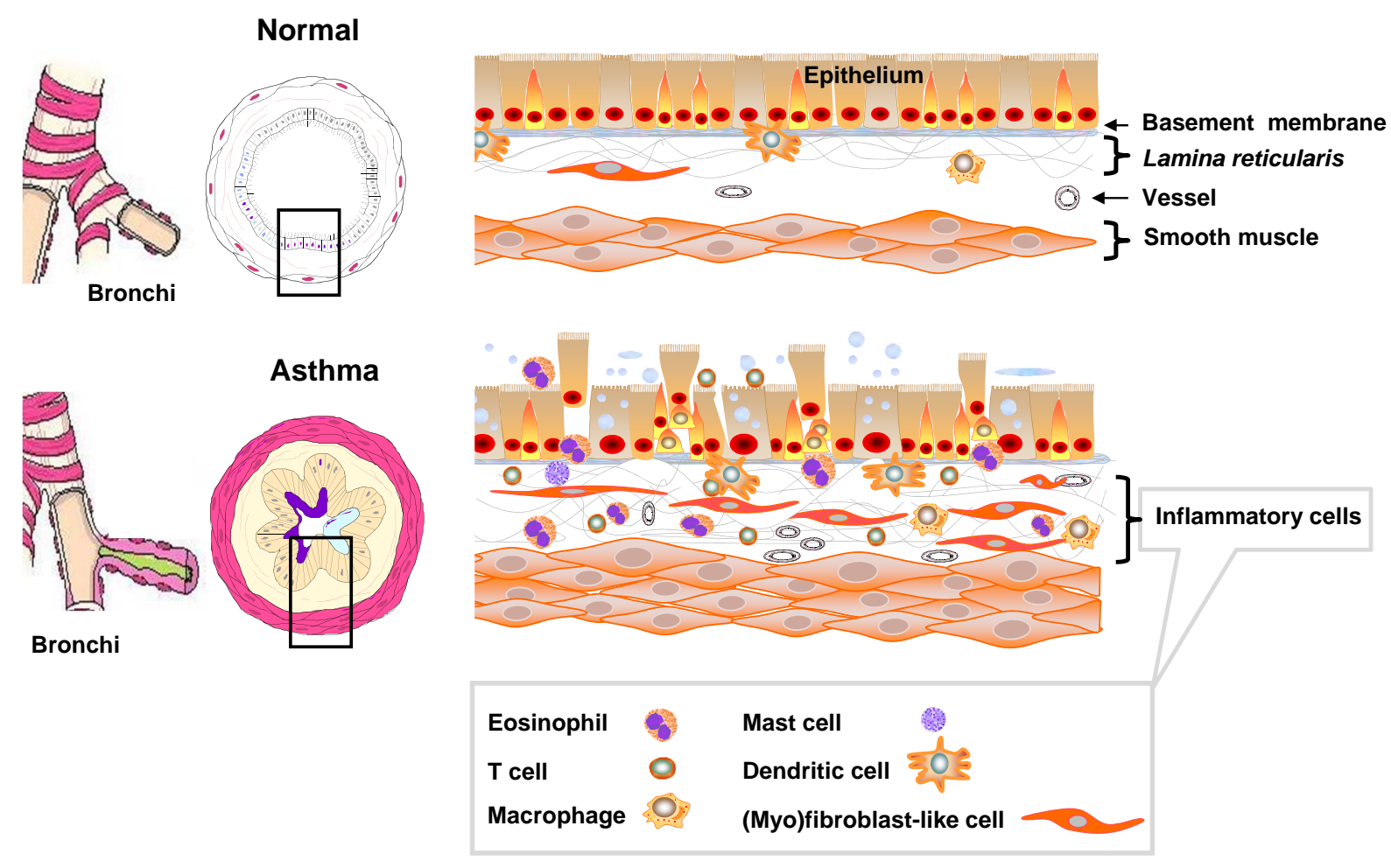

Fig. (1). Schematic illustration of the inflammatory and structural changes in the bronchial wall of asthmatic patients. Designed by using objects of the SmartDraw 2007 software (SmartDraw.com, San Diego, CA, USA) and the ScienceSlides 2005 software (VisiScience Corporation, Chapel Hill, NC, USA).

severe disease when it is frequently associated with an increased hypertrophy and hyperplasia of the underlying smooth muscle layer [26,27].

\section{FIBROCYTE CONTRIBUTION TO AIRWAY RE- MODELING IN ASTHMA}

In the last decade, several studies have provided mounting evidence that many bronchial fibroblast- and myofibroblast-like cells in asthma exhibit the phenotypic and functional characteristics of fibrocytes [28-32]. The fibrocytes are bone marrow-derived CD45+CD45RO+CD34+ CD11b+ CD13+HLA-DR+ progenitors, with mixing features of myeloid cells and fibroblasts, which constitutively produce collagens and differentiate into spindle-shaped $\alpha$-SMA-positive cells similar to myofibroblasts upon appropriate in-vitro stimulation or following their migration from the circulation to acutely injured or chronically inflamed tissues [33,34]. In healthy individuals, the frequency of authentic mature fibrocytes (cells that uniquely co-express CD34, CD45RO, COL1 mRNA and COL1 protein) in the peripheral blood is very low, with numbers ranging from 1400 to $8200 / \mathrm{ml}$ [32]. This fact explains why it is possible to obtain a sufficient number of normal fibrocytes for in-vitro testing solely in long-term cultures of peripheral blood mononuclear cells which selectively favor the proliferation, differentiation and survival of this cell population $[35,36]$. By contrast, there is a marked increase in the number of peripheral blood fibrocytes in patients with allergen-exacerbated asthma or chronically se- vere, treatment-refractory disease [31, 32, 37, 39]. In two studies including atopic and non-atopic non-asthmatic individuals, patients with non-severe/treatment responsive asthma, patients with severe/treatment-refractory disease and subjects tested during an acute exacerbation of asthma, the median number of fibrocytes isolated from the leukocyterich fraction of the peripheral blood was $8000 / \mathrm{ml}, 17000 / \mathrm{ml}$, $46000 / \mathrm{ml}$, and $69000 / \mathrm{ml}$, respectively [38, 39].

The circulating fibrocytes from patients with an acute exacerbation of asthma and patients with chronically severe/treatment-refractory disease migrate and proliferate in response to cytokines and growth factors released in excessive amounts in the airways of asthmatic individuals, produce collagenous and non-collagenous ECM components specifically increased in the asthmatic bronchial mucosa, and differentiate into myofibroblast-like cells when stimulated with factors present in the autologous sputum $[32,38,39]$.

Analyses of bronchial biopsy specimens from healthy individuals have demonstrated that there are only a few or no fibrocytes in the bronchial mucosa of these subjects [29], [31]. Similar analyses of bronchial biopsy specimens from asthmatic patients with various levels of disease severity have revealed the presence of an appreciable number of CD34 ${ }^{+}$cells and CD34+CD45RO+ cells that actively sensitize COL1 and express $\alpha$-SMA [28-31]. These mature fibrocytes localize to areas of ECM deposition in the subepithelial zone [28 29,31] and also infiltrate the underlying smooth muscle bundle in some patients [29,31], particularly in those 
with severe, treatment-refractory asthma [31]. The density of fibrocytes beneath the epithelial basement membrane correlates with the thickness of the lamina reticularis [29], which reflects the magnitude of subepithelial fibrosis. Fibrocyte infiltration of the subepithelial area also increases in patients requiring more intensive treatment to achieve disease control [31]. The highest densities of fibrocytes in the lamina propria have been detected in patients not receiving an antiinflammatory treatment [29] and in those who suffers from severe asthma despite the use of elevated doses of topical corticosteroids or oral corticosteroid treatment [31]. In cases where there is a prominent fibrocytes infiltration of the subepithelial zone it is possible to isolate CD34+COL1+ $\alpha-$ SMA+ fibrocytes in cultures of cells obtained by bronchoalveolare lavage [29]. During an acute exacerbation of the disease, fibrocytes co-expressing CD34, CD45RO and COL1 mRNA are also present in the induced sputum [32].

In allergic patients with treatment-responsive and wellcontrolled asthma in absence of allergen exposure, the density of fibrocytes actively synthesizing COL1 markedly increases in the subepithelial zone within 24 hours following the inhalation of the clinically relevant allergen, and significant proportions of these cells also express $\alpha$-SMA [28]. The time-course of allergen-induced fibrocytes accumulation and frequency of a $\alpha$-SMA+ fibrocytes are consistent with more recently reported observations on the accumulation of fibroblast- and myofibroblast-like cells of undefined origin and phenotype in similarly allergen-exposed asthmatic individuals [25]. Moreover, certain functional characteristics of fibrocytes [32, 40, 41] are remarkably similar to those reported for bronchial fibroblast- and myofibroblast-like cells directly isolated from asthmatic airways [42, 43], including the pattern of cytokine production, the in-vitro susceptibility to viral infections and the response to viral stimulation.

All these findings suggest a major role of fibrocytes in the genesis and progression of airway remodeling in asthma. Their important contribution to the development of irreversible airflow obstruction is supported by the existence of a significant correlation between the number of circulating COL1-producing fibrocytes and the magnitude of the yearly decline in lung function in patients with treatment-refractory asthma who already exhibit fixed airway narrowing [37]. Although there is at present no evidence of a statistically significant correlation between the number of peripheral blood fibrocytes and the density of fibrocytes in the bronchial mucosa, the in-vitro observations that circulating fibrocytes form symptomatic asthmatics migrate and differentiate in response to chemokines and growth factors present in increased amounts in the autologous sputum [39] strongly suggest an active recruitment of fibrocytes from the circulation during disease exacerbations and in treatment-resistant asthma. Fig. (2) shows representative microphotographs of fibrocytes detected in the induced sputum and peripheral blood of patients with uncontrolled asthma [32] and the ef-
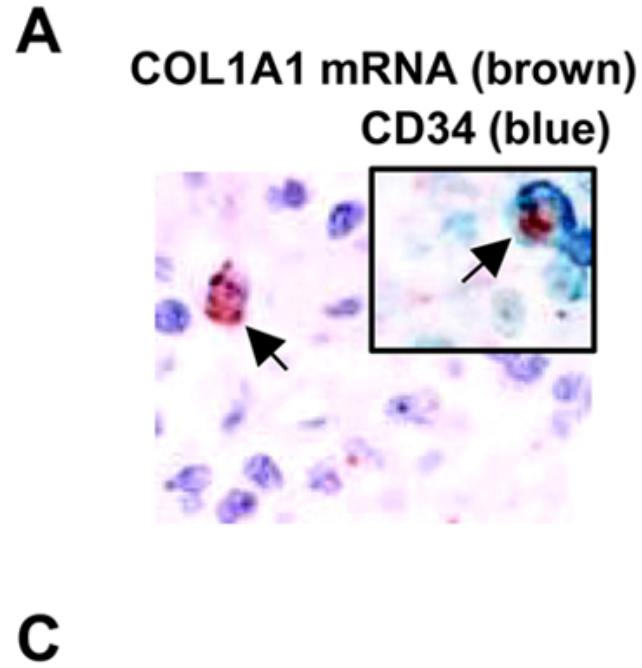

COL3A1

$\beta$-tubulin

$\begin{array}{llll}12 & 24 & 72 & \text { hours }\end{array}$

B

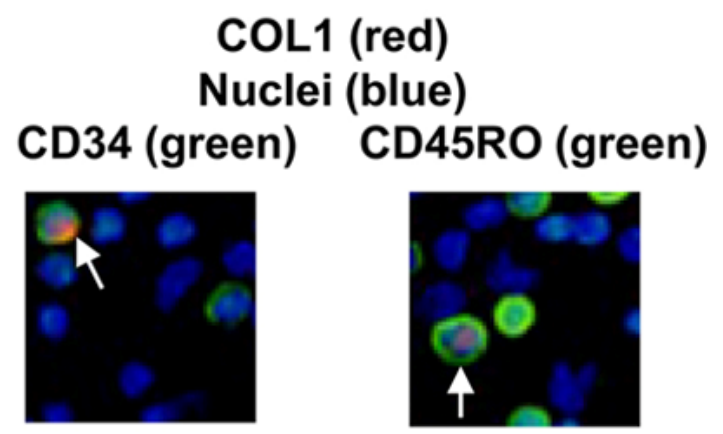

D

\section{$\alpha-S M A$ (red) Nuclei (blue)}

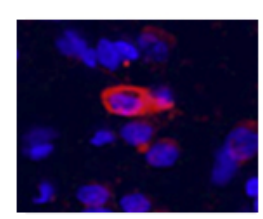

24 hours

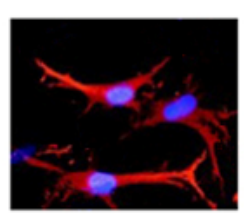

72 hours

Fig. (2). Identification of fibrocytes in the induced sputum (A) and in the peripheral blood (B) of patients with uncontrolled asthma and effects of stimulation with the fluid phase of induced sputum on the expression of the $\alpha 1$ chain of COL3 (COL3A1) (C) and $\alpha$-SMA (D) at the indicated points in time in autologous circulating fibrocytes [32], [38]. Fibrocytes in induced sputum were identified as cells co-expressing CD34 and the mRNA for the $\alpha 1$ chain of COL1 (COL1A1) by using a double immunohistochemical and in-situ hybridization technique [32]. 
fects of stimulation with the fluid phase of induced sputum on the expression of COL3 and $\alpha$-SMA in autologous circulating fibrocytes [38].

\section{CONTRIBUTION OF EPITHELIAL CELL-DERIVED FACTORS TO FIBROCYTE ACCUMULATION AND DIFFERENTIATION IN ASTHMA}

The results of the studies discussed above concur to suggest that the asthmatic bronchial epithelium may represent a major source of fibrocyte chemoattractants and growth factors. Epithelial cell-derived chemokines may be involved in the airway recruitment of fibrocytes from the peripheral blood because fibrocyte infiltration of the bronchial mucosa is particularly evident in the subepithelial zone $[28,29]$. Moreover, fibrocytes that have recently migrated toward the epithelium can be recovered from the asthmatic airways by using procedures that mainly sample cells present within or in close proximity of the epithelium, such as bronchoalveolar lavage [29] and sputum induction [32]. A study that tracked the migration of labeled circulating fibrocytes to the inflamed airways in a mouse model of chronic allergic asthma also demonstrated the predominant localization of recruited cells to the subepithelial zone of the bronchial wall [28]. Some of the mechanisms through which the epithelium may potentially drive the accumulation and local differentiation of fibrocytes in asthma have been recently identified (Fig. 3) and will be discussed in this section.

The circulating fibrocytes from patients with an acute exacerbation of asthma and asthmatic individuals with persistently severe/treatment-refractory disease express the receptors for some of the chemokines/cytokines and growth factors involved in asthma pathogenesis at higher levels than the circulating fibrocytes from patients with non-severe/treatment-responsive asthma or non-asthmatic subjects [32, 38, 39, 44]. The receptors for the C-C motif chemokine ligands (CCLs) CCL5 (also known as regulated on activation normal $\mathrm{T}$ cell expressed and secreted or RANTES), CCL11 (also known as eotaxin) and CCL24 (also known as eotaxin

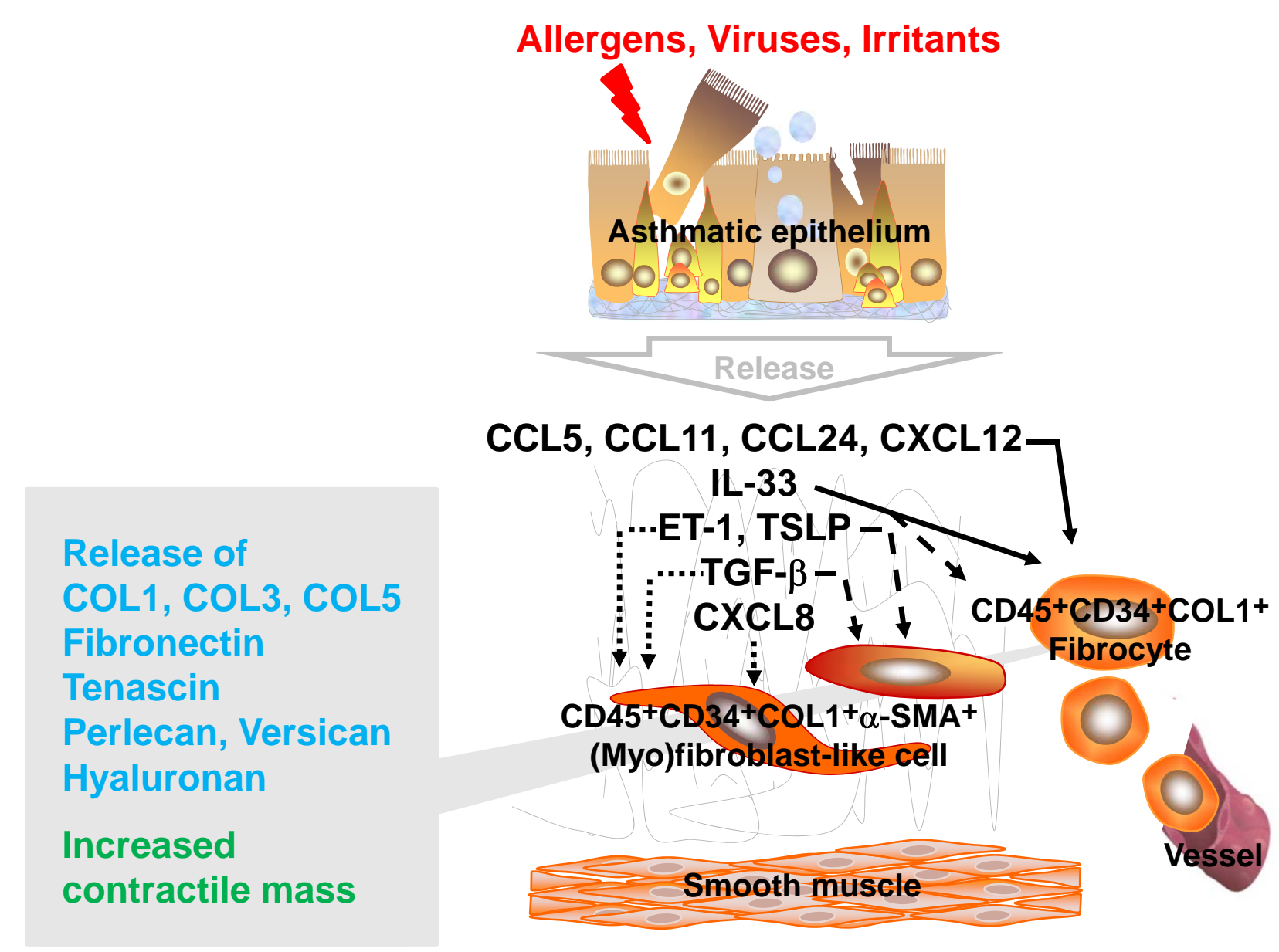

Migration $\longrightarrow \quad$ Proliferation $--\rightarrow \quad$ Differentiation $\quad \cdots . . . . .$.

Fig. (3). Schematic illustration of the mechanisms of action of epithelial cell-derived factors that may potentially promote the accumulation and profibrotic function of fibrocytes in the bronchial mucosa of asthmatic patients. Designed by using objects of the ScienceSlides 2005 software (VisiScience Corporation, Chapel Hill, NC, USA). 
2 or myeloid progenitor inhibitor factor-2) are functional receptors [39]. Their ligands are mainly produced by bronchial epithelial cells and are known to play a major role in the airway recruitment of eosinophils in asthma [45-48]. Recombinant CCL5, CCL11 and CCL24 induce the migration of circulating fibrocytes from patients with severe/treatment-refractory asthma in a dose-dependent manner and endogenous CCL5, CCL11 and CCL24 significantly contribute to various extents to the fibrocyte chemotactic activity of the induced sputum from these subjects [39]. The existence of a relationship between the increased release of CCL11 from the asthmatic epithelium and the accumulation of fibrocytes in the bronchial mucosa is also supported by the combined results of two studies that evaluated the kinetics of CCL11 expression [47] and the time-course of the recruitment of eosinophils [47] and fibrocytes [28] in the airways of the same patients during an allergen-induced asthmatic response. The peak increase in CCL11 production occurred at 4 hours post-allergen inhalation, as assessed by examining the expression of CCL11 mRNA and protein in bronchial biopsies and by measuring the concentrations of immunoreactive CCL11 in the bronchoalveolar lavage fluid [47]. When sections of the same biopsy specimens were evaluated at a later stage to enumerate fibrocytes, it was evident that the peak increase in CCL11 production induced by allergen inhalation coincided with the first detectable increase in fibrocyte number in the bronchial mucosa [28]. Taken together, the results of the studies mentioned above may explain the reason why fibrocyte infiltration of the asthmatic airways and sputum fibrocytosis are most frequently observed in association with bronchial and sputum eosinophilia [31, 32].
Another epithelial cell-derived factor involved in the genesis and persistence of airway inflammation in asthma is interleukin (IL)-33 [49,50]. This member of the IL-1 cytokine family is released from injured cells (e.g. cells exposed to allergens with proteolytic activity such as house dust mite allergens, infected cells, or cells subjected to mechanical injury) and it is considered to promote allergen-induced and innate inflammatory responses by functioning as an endogenous danger signal $[49,50]$. Increased quantities of immunoreactive IL-33 have been detected in the peripheral blood [51] and in the bronchoalveolar lavage fluid [52] of asthmatic patients and the bronchial epithelium of these subjects produce IL-33 at high levels [52]. Such an excessive release of IL-33 in asthmatic airways may occur in response to viral infections, exposure to allergens or as a result of the mechanical stress generated on the inflamed epithelium by repeated episodes of airflow obstructions. The circulating fibrocytes from patients with transiently uncontrolled allergic asthma show increased levels of expression of the specific receptor for IL-33 on their surface and IL-33 induces strong chemotactic and proliferative responses in these cells [38]. Moreover, the concentrations of IL-33 in the sputum of patients with transiently uncontrolled asthma significantly correlate with the number of sputum fibrocytes and the frequency of asthma symptoms in the previous week (Fig. 4).

Active signaling of epithelial cell- and eosinophil-derived transforming growth factor- $\beta$ (TGF- $\beta$ ) [53-55] and increased production of endothelin (ET)-1 in the bronchial epithelium [56-59] have been implicated in the pathogenesis of airway remodeling in asthma. Both TGF- $\beta[28,35]$ and ET-1 [28] induce the differentiation of cultured fibrocytes into fibroblast- and myofibroblast-like cells that produce higher
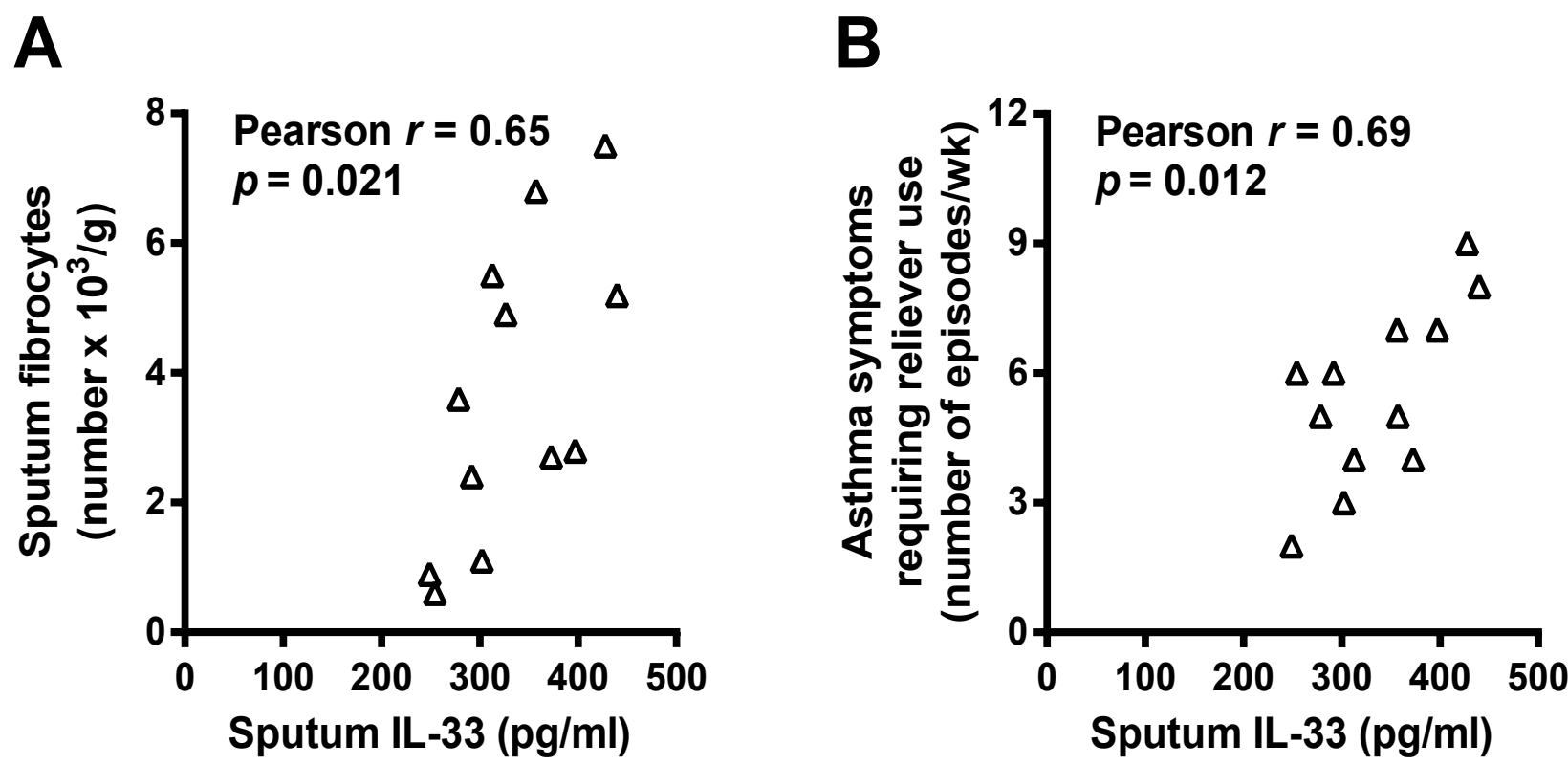

Fig. (4). Evidence that the levels of sputum IL-33 in patients with uncontrolled asthma significantly correlate with the numbers of sputum fibrocytes (A) and with the frequency of asthma symptoms requiring reliever (short-acting bronchodilator) use during the day and/or at night in the previous week (B). The concentrations of IL-33 in the fluid phase of induced sputum were determined with the use of a commercially available enzyme-linked immunosorbent assay (Enzo Life Sciences). Fibrocytes in induced sputum were identified as cells co-expressing CD34 and the mRNA for the $\alpha 1$ chain of COL1 (COL1A1) by using a double immunohistochemical and in-situ hybridization technique [32]. The relationship between two sets of variables was evaluated by calculating the Pearson correlation coefficient. 
amounts of COL1 and COL3 and more frequently acquire $\alpha$ SMA expression in comparison with unstimulated cells. Both TGF- $\beta$ and ET- 1 also promote the expansion of the fibrocyte population in vitro [28]. During an allergeninduced asthmatic response, the increased accumulation of fibrocytes in the bronchial mucosa of asthmatic individuals is paralleled by the enhanced production of ET- 1 in bronchial epithelial cells and endothelial cells and by the augmented release of TGF- $\beta$ from epithelial cells and eosinophils [60]. The peak increase in ET- 1 and TGF- $\beta$ release in the airways is observed at 24 hours following allergen inhalation, when an appreciable proportion of fibrocytes have acquired the myofibroblast marker $\alpha$-SMA. A study in an animal model of chronic allergic asthma also supports the hypothesis that TGF- $\beta$ may play a major role in the airway accumulation of fibrocytes and their further differentiation into fibroblast- and myofibroblast-like cells [28,61]. In this study, repeated allergen inhalation challenges of systemically sensitized mice for up to 8 weeks resulted in the progressive infiltration of the bronchial wall with CD34+COL1+ fibrocytes. Over the last 2 weeks of chronic allergen exposure, the mean percentage of collagen-producing fibrocytes that also expressed $\alpha$-SMA in the bronchial subepithelial zone increased from $32 \%$ to $45 \%$ [28]. The progressive increase in the density of fibrocytes beneath the epithelium correlated with the level of TGF- $\beta$ immunoreactivity in the bronchial wall and with the magnitude of collagen deposition [61].

The C-X-C chemokine motif ligand 8 (CXCL8, also known as IL-8) is another cytokine expressed at high level in the bronchial epithelium of asthmatic patients [62]. The excessive production of CXCL8 is particularly evident in the airways of individuals with severe disease and is believed to contribute to the airway recruitment of neutrophils and to the expansion of the contractile mass in these patients [62-65]. IL-17A (also known as IL-17) is one of the many cytokines that may upregulate the secretion of CXCL8 in the asthmatic epithelium [66]. It also promotes the release of CXCL8 in circulating fibrocytes from patients with allergen-exacerbated asthma [32]. Following stimulation with IL-17A, these cells express increased levels of $\alpha$-SMA, without showing an increased production of collagens [32]. Such phenomenon is not apparently associated with activation of TGF- $\beta$ signaling but can be inhibited by blocking the effects of the IL-17Ainduced release of CXCL8 from fibrocytes themselves [32]. Other studies have demonstrated that human CXCL8 [67], [68] and its chicken orthologue [69] can induce $\alpha$-SMA in fibroblast-like cells and hepatic stellate cells and that CXCL8 may work independently from TGF- $\beta$ [68]. The mechanisms involved in the CXCL8-mediated induction of $\alpha$-SMA remain unclear. Nonetheless, the available data strongly suggest that epithelial CXCL8 may directly or indirectly contribute to promote the differentiation of fibrocytes into myofibroblast-like cells once circulating fibrocytes have migrated to the bronchial mucosa of asthmatic patients.

Cultured human and murine fibrocytes express the receptor for CXCL12 (also known as stromal cell-derived factor1) [35], a cytokine produced by bronchial epithelial cells and potentially involved in the promotion of airway inflamma- tion in asthma [70, 71]. CXCL12 induces a migratory response in bone marrow-derived progenitors and inflammatory cells by aptotaxis, after binding to ECM components such as fibronectin and proteoglycans [72-75]. This mechanism of action explains the results of the original study mentioned above [35], where CXCL12 was unable to function as a fibrocyte chemoattractant in vitro, when tested in a standard chemotaxis assay, and did not induce the migration of circulating fibrocytes to the normal skin in vivo, following intradermal injection of the recombinant protein in mice. In agreement with the aptotactic effect of CXCL12, significant migratory responses of human fibrocytes to the recombinant cytokine were observed in an in-vitro assay employing fibronectin-coated filters and prolonged incubation periods [76]. Considering that the bronchial mucosa of asthmatic patients usually shows an increased deposition of fibronectin and proteoglycans beneath the epithelial basement membrane [9-11], it is reasonable to hypothesize that epithelial cell-derived CXCL12 may bind to these ECM components and guide the migration of fibrocytes and inflammatory cells toward the epithelium following their recruitment from the circulation as result of the excessive release of chemokines in the asthmatic airways.

Thymic stromal lymphopoietin (TSLP) is a cytokine produced by the airway and skin epithelia in response to a variety of antigenic and environmental stimuli and is considered an important promoter of allergic inflammation [77]. TSLP production is increased in asthmatic airways and the magnitude of expression of this cytokine in the asthmatic epithelium correlate with the levels of disease severity [78]. A recent study [79] revealed the presence of elevated numbers of CD34+COL1+ fibrocytes in the fibrotic skin lesions of subjects affected by chronic atopic dermatitis. These cells expressed the TSLP receptor and experiments in a model of IL13-induced fibrotic dermatitis in mice provided evidence of the potential involvement of epithelial cell-derived TSLP in the proliferation and further differentiation of fibrocytes at tissue site. A similar mechanism may also contribute to the accumulation and local differentiation of fibrocytes in other chronic allergic inflammatory disorders driven by helper type $2 \mathrm{~T}$ cell-derived cytokines and associated with fibrotic tissue remodeling, particularly chronic allergic asthma.

The studies discussed above have uncovered important pathways through which the bronchial epithelium may drive the accumulation and profibrotic function of fibrocytes in asthma. Fig. (3) schematically summarize how epithelial cell-derived factors may potentially induce the progression of fibrotic changes and increase the mass of contractile cells in the bronchial wall of asthmatic patients by promoting fibrocyte recruitment and the local differentiation of these cells into fibroblast- and myofibroblast-like cells.

\section{BENEFICIAL AND DELETERIOUS EFFECTS OF FI- BROCYTE ACCUMULATION ON EPITHELIAL IN- TEGRITY AND FUNCTION}

Circulating fibrocytes are actively recruited from the circulation at an early stage of wound healing [80] and increasing fibrocyte accumulation at the wounded site accelerate 
wound repair [81, 82]. The ability of fibrocytes to facilitate tissue repair after injury has been related to their production of ECM components, ECM-degrading enzymes, proangiogenic factors and cytokines that induce the migration and proliferation of epithelial cells such as fibroblast growth factor (FGF)-7 [82]. Fibrocytes that acquire the expression of $\alpha$-SMA following their migration to the wounded tissue also have contractile properties that favor wound closure [80][82]. However, the bronchial mucosa of asthmatic patients resembles a chronic wound where neither the inflammatory phase nor the reparative phase resolve completely [61]. The inflammatory reaction is likely increased as a result of fibrocyte accumulation, because fibrocytes from asthmatic patients produce high quantities of proinflammatory cytokines such as CXCL1, CXCL8, IL-6 and tumor necrosis factor $\alpha$ (TNF $\alpha$ ) [32, 38] (Fig. 5). In this situation, the production of FGF-7 and ECM-degrading enzymes that also degrade the epithelial basement membrane, such as matrix metalloprotease-9 (MMP-9) may have deleterious rather than beneficial effects on the integrity and function of the asthmatic bronchial epithelium (Fig. 5).

It is worth noting that the collagen and proteoglycan gene expression profile of fibrocytes would suggest that the main function of fibrocytes is tissue stabilization [36]. Thus, the fibrotic changes specifically induced by fibrocytes and the contractile force generated by $\alpha$-SMA+ fibrocytes in the subepithelial zone may concur to prevent further structural damage during repeated episodes of bronchial constriction in transiently uncontrolled or treatment-refractory asthma by enhancing the resistance to mechanical stress of an epithelial barrier weakened by the chronic inflammatory process [36, 60, 61] (Fig. 5).

\section{CONCLUSION}

There is increasing evidence that circulating fibrocytes may serve as a renewable source of fibroblast- and myofibroblast-like cells in the chronically inflamed airways of asthmatic patients and that fibrocyte accumulation may contribute to the progression of irreversible structural changes leading to fixed airway narrowing. The asthmatic bronchial epithelium is a major producer of potent fibrocyte chemoattractants and growth factors and may play a key role in the development and progression of airway remodeling by promoting the recruitment, local proliferation, and differentiation of fibrocytes (Fig. 3). The accumulation of fibrocytes in the subepithelial zone may have both beneficial and detrimental effects on epithelial integrity and function. On the one hand, fibrocytes may enhance inflammation, promote the disruption of the epithelial basement membrane and contribute to a dysregulated proliferation of epithelial cells. On the other hand, fibrocytes may have a tissue-stabilizing effect and may increase the resistance to mechanical stress of the epithelial barrier.
ABBREVIATIONS
$\alpha$-SMA $=\alpha$-smooth muscle actin
$\mathrm{CCL}=\mathrm{C}-\mathrm{C}$ motif chemokine ligand
COL1 = Type I collagen
COL1A1 $=\alpha 1$ chain of COL1
COL3 = Type III collagen
COL3A1 $=\alpha 1$ chain of COL3
COL5 = Type $\mathrm{V}$ collagen

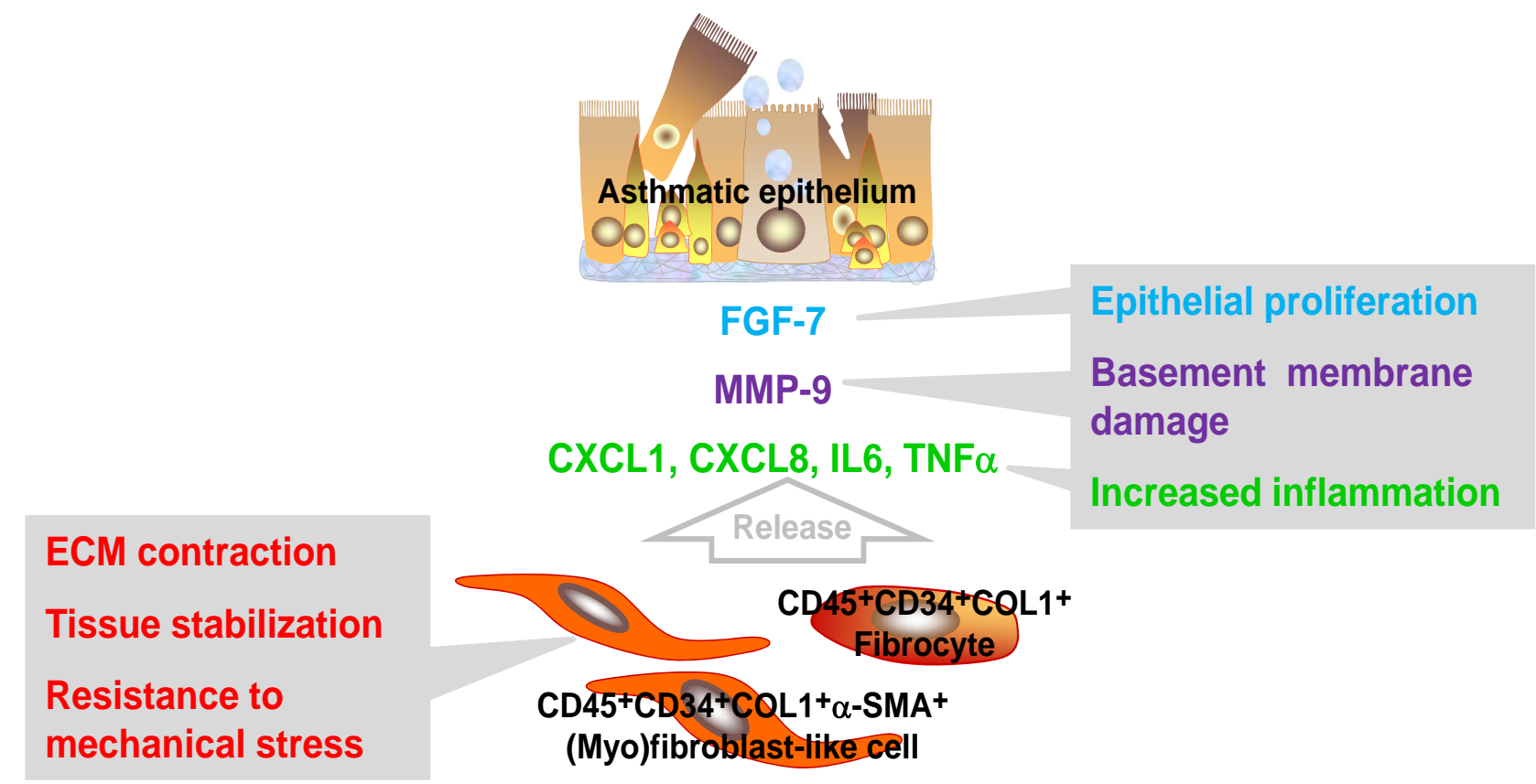

Smooth muscle

Fig. (5). Schematic illustration of the possible effects of fibrocyte accumulation on epithelial integrity and function in asthma. Designed by using objects of the ScienceSlides 2005 software (VisiScience Corporation, Chapel Hill, NC, USA). 


$$
\begin{aligned}
& \text { CXCL }=\text { C-X-C motif chemokine ligand } \\
& \text { ECM } \\
& \text { ET-1 }=\text { Extracellular matrix } \\
& \text { FGF-7 }=\text { Fibroblast growth factor-7 } \\
& \text { IL }=\text { Interleukin } \\
& \text { MMP-9 }=\text { Matrix metalloprotease-9 } \\
& \text { TGF- } \beta=\text { Transforming growth factor- } \beta \\
& \text { TNF } \alpha=\text { Tumor necrosis factor } \alpha \\
& \text { TSLP }=\text { Thymic stromal lymphopoietin }
\end{aligned}
$$

\section{CONFLICTS OF INTEREST}

S. Mattoli is a founding shareholder and board member of AVAIL GmbH. The other authors have no potential conflicts of interest or financial interests to disclose.

\section{ACKNOWLEDGEMENTS}

None Declared.

\section{REFERENCES}

[1] National asthma education and prevention program. Expert Panel Report 3 (EPR-3): Guidelines for the Diagnosis and Management of Asthma - Summary Report 2007. J Allergy Clin Immunol 2007; 120(5 Suppl): S94-S138.

[2] Jeffery PK. Remodeling and inflammation of bronchi in asthma and chronic obstructive pulmonary disease. Proc Am Thorac Soc 2004; 1: 176-83.

[3] Durrani SR, Viswanathan RK, Busse WW. What effect does asthma treatment have on airway remodeling? Current perspectives. J Allergy Clin Immunol 2011; 128: 439-48.

[4] Roche WR, Beasley R, Williams JH, Holgate ST. Subepithelial fibrosis in the bronchi of asthmatics. Lancet 1989; 1: 520-4.

[5] Ebina M, Takahashi T, Chiba T, Motomiya M. Cellular hypertrophy and hyperplasia of airway smooth muscles underlying bronchial asthma. A 3-D morphometric study. Am Rev Respir Dis 1993; 148: 720-6.

[6] Cohen L, Xueping E, Tarsi J, et al. Epithelial cell proliferation contributes to airway remodeling in severe asthma. Am J Respir Crit Care Med 2007; 176: 138-45.

[7] Halwani R, Al-Muhsen S, Hamid Q. Airway remodeling in asthma. Curr Opin Pharmacol 2010; 10: 236-45.

[8] Detoraki A, Granata F, Staibano S, Rossi FW, Marone G, Genovese A. Angiogenesis and lymphangiogenesis in bronchial asthma. Allergy 2010; 65: 946-58.

[9] Roberts CR. Is asthma a fibrotic disease? Chest 1995; 107(3 Suppl): 111S-7S.

[10] Huang J, Olivenstein R, Taha R, Hamid Q, Ludwig M. Enhanced proteoglycan deposition in the airway wall of atopic asthmatics. Am J Respir Crit Care Med 1999; 160: 725-9.

[11] Pini L, Hamid Q, Shannon J, et al. Differences in proteoglycans deposition in the airways of moderate and severe asthmatics. Eur Respir J 2007; 29: 71-7.

[12] Pohunek P, Warner JO, Turzikova J, Kudrmann J, Roche WR. Markers of eosinophil inflammation and tissue re-modelling in children before clinically diagnosed bronchial asthma. Pediatr Allergy Immunol 2005; 16: 43-51.

[13] Payne DN, Rogers AV, Aderoth E, et al. Early thickening of the reticular basement membrane in children with difficult asthma. Am J Respir Crit Care Med 2003; 167: 78-82.

[14] Kasahara K, Shiba K, Ozawa T, Okuda K, Adachi M. Correlation between the bronchial subepithelial layer and whole airway wall thickness in patients with asthma. Thorax 2002; 57: 242-6.

[15] Fish JE, Peters SP. Airway remodeling and persistent airway obstruction in asthma. J Allergy Clin Immunol 1999; 104: 509-16.
Shiba K, Kasahara K, Nakajima H, Adachi M. Structural changes of the airway wall impair respiratory function, even in mild asthma. Chest 2002; 122: 1622-6.

Milanese M, Crimi E, Scordamaglia A, et al. On the functional consequences of bronchial basement membrane thickening. J Appl Physiol 2001; 91: 1035-40.

Ward C, Johns DP, Bish R, et al. Reduced airway distensibility, fixed airflow limitation, and airway wall remodeling in asthma. Am J Respir Crit Care Med 2001; 164: 1718-21.

Pascual RM, Peters SP. The irreversible component of persistent asthma. J Allergy Clin Immunol 2009; 124: 883-90.

Brewster CEP, Howarth PH, Djukanovic R, Wilson J, Holgate ST, Roche WR. Myofibroblasts and subepthelial fibrosis in bronchial asthma. Am J Respir Cell Mol Biol 1990; 3: 507-11.

Holgate ST, Davies DE, Lackie PM, Wilson SJ, Puddicombe SM, Lordan JL. Epithelial-mesenchymal interaction in the pathogenesis of asthma. J Allergy Clin Immunol 2000; 105: 193-204.

[22] Minshall EM, Leung D, Martin R, et al. Eosinophil-associated TGF- $\beta 1$ mRNA expression and airway fibrosis in bronchial asthma. Am J Respir Cell Mol Biol 1997; 17: 326-33.

[23] Bousquet J, Jeffery PK, Busse WW, Johnson M, Vignola AM. Asthma: from bronchoconstriction to airway inflammation and remodeling. Am J Respir Crit Care Med 2000; 161: 1720-45.

[24] Humbles AA, Lloyd CM, McMillan SJ, et al. A critical role for eosinophils in allergic airway remodeling. Science 2004; 305: 1776-9.

[25] Kariyawasam HH, Aizen M, Barkans J, Robinson DS, Kay AB. Remodeling and airway hyperesponsiveness but not cellular inflammation persist after allergen challenge in asthma. Am J Respir Crit Care Med 2007; 175: 896-904.

[26] Benayoun L, Druilhe A, Dombret MC, Aubier M, Pretolani M. Airway structural alterations selectively associated with severe asthma. Am J Respir Crit Care Med 2003; 167: 1360-8.

[27] Pepe C, Foley S, Shannon J, et al. Differences in airway remodeling between subjects with severe and moderate asthma. J Allergy Clin Immunol 2005; 116: 544-9.

[28] Schmidt M, Sun G, Stacey MA, Mori L, Mattoli S. Identification of circulating fibrocytes as precursors of bronchial myofibroblasts in asthma. J Immunol 2003; 171: 380-9.

[29] Nihlberg K, Larsen K, Hultgårdh-Nilsson A, Malmström A, Bjermer L, Westergren-Thorsson G. Tissue fibrocytes in patients with mild asthma: a possible link to thickness of reticular basement membrane? Respir Res 2006; 7: 50.

[30] Larsen K, Macleod D, Nihlberg K, et al. Specific haptoglobin expression in bronchoalveolar lavage during differentiation of circulating fibroblast progenitor cells in mild asthma. J Proteome Res 2006; 5: 1479-83.

[31] Saunders R, Siddiqui S, Kaur D, et al. Fibrocyte localization to the airway smooth muscle is a feature of asthma. J Allergy Clin Immunol 2009; 123: 376-84.

[32] Bellini A, Marini MA, Bianchetti L, Barczyk M, Schmidt M, Mattoli S. Interleukin (IL)-4, IL-13, and IL-17A differentially affect the profibrotic and proinflammatory functions of fibrocytes from asthmatic patients. Mucosal Immunol 2012; 5: 140-9

[33] Mattoli S, Bellini A, Schmidt M. The role of a human hematopoietic mesenchymal progenitor in wound healing and fibrotic diseases and implications for therapy. Curr Stem Cell Res Ther 2009; 4: 266-80.

[34] Herzog EL, Bucala R. Fibrocytes in health and disease. Exp Hematol 2010; 38: 548-56.

[35] Abe R, Donnelly SC, Peng T, Bucala R, Metz CN. Peripheral blood fibrocytes: differentiation pathway and migration to wound sites. J Immunol 2001; 166: 7556-62.

[36] Bianchetti L, Barczyk M, Cardoso J, Schmidt M, Bellini A, Mattoli S. Extracellular matrix remodelling properties of fibrocytes. J Cell Mol Med 2012; 16: 483-95.

[37] Wang CH, Huang CD, Lin HC, et al. Increased circulating fibrocytes in asthma with chronic airflow obstruction. Am J Respir Crit Care Med 2008; 178: 583-91.

[38] Bianchetti L, Marini MA, Isgrò M, Bellini A, Schmidt M, Mattoli S. IL-33 promotes the migration and proliferation of circulating fi- 
brocytes from allergen-exacerbated asthma. Biochem Biophys Res Commun 2012; 426: 116-21.

[39] Isgrò M, Bianchetti L, Marini MA, Bellini A, Schmidt M, Mattoli S. The C-C motif chemokine ligands CCL5, CCL11, and CCL24 induce the migration of circulating fibrocytes from patients with severe asthma. Mucosal Immunol 2012. [Epub ahead of print].

[40] Chesney J, Metz C, Stavitsky AB, Bacher M, Bucala R. Regulated production of type I collagen and inflammatory cytokines by peripheral blood fibrocytes. J Immunol 1998; 160: 419-25.

[41] Balmelli C, Alves MP, Steiner E, et al. Responsiveness of fibrocytes to toll-like receptor danger signals. Immunobiology 2008; 212: 693-9.

[42] Zhang S, Howarth PH, Roche WR. Cytokine production by cell cultures from bronchial subepithelial myofibroblasts. J Pathol 1996; 180: 95-101.

[43] Bedke N, Haitchi HM, Xatzipsalti M, Holgate ST, Davies DE. Contribution of bronchial fibroblasts to the antiviral response in asthma. J Immunol 2009; 182: 3660-7.

[44] Wang CH, Huang CD, Lin HC, et al. Increased activation of fibrocytes in patients with chronic obstructive asthma through an epidermal growth factor receptor-dependent pathway. J Allergy Clin Immunol 2012; 129: 1367-76.

[45] Mattoli S, Stacey MA, Sun G, Bellini A, Marini M. Eotaxin expression and eosinophilic inflammation in asthma. Biochem Biophys Res Commun 1997; 236: 299-301.

[46] Ying S, Robinson DS, Meng Q, et al. Enhanced expression of eotaxin and CCR3 mRNA and protein in atopic asthma: association with airway hyperresponsiveness and predominant colocalization of eotaxin mRNA to bronchial epithelial and endothelial cells. Eur J Immunol 1997; 27: 3507-16.

[47] Brown JR, Kleimberg J, Marini M, Sun G, Bellini A, Mattoli S. Kinetics of eotaxin expression and its relationship to eosinophil accumulation and activation in bronchial biopsies and bronchoalveolar lavage of asthmatic patients after allergen inhalation. Clin Exp Immunol 1998; 114: 137-46.

[48] Ying S, Meng Q, Zeibecoglou K, et al. Eosinophil chemotactic chemokines (eotaxin, eotaxin-2, RANTES, monocyte chemoattractant protein-3 [MCP-3], and MCP-4), and C-C chemokine receptor 3 expression in bronchial biopsies from atopic and nonatopic (intrinsic) asthmatics. J Immunol 1999; 163: 6321-9.

[49] Borish L, Steinke JW. Interleukin-33 in asthma: how big of a role does it play? Curr Allergy Asthma Rep 2011; 11: 7-11.

[50] Oboki K, Nakae, Matsumoto K, Saito H. IL-33 and airway inflammation, Allergy Asthma Immunol Res 2011; 3: 81-8.

[51] Glück J, Rymarczyk B, Rogala B. Serum IL-33 but not ST2 level is elevated in intermittent allergic rhinitis and is a marker of the disease severity. Inflamm Res 2012; 61: 547-50.

[52] Préfontaine D, Nadigel J, Chouiali F, et al. Increased IL-33 expression by epithelial cells in bronchial asthma. J Allergy Clin Immunol 2010; 125: 752-4.

[53] Phipps S, Benyahia F, Ou TT, Barkans J, Robinson DS, Kay AB. Acute allergen-induced airway remodeling in atopic asthma. Am J Respir Cell Mol Biol 2004; 31: 626-32.

[54] Sagara H, Okada T, Okumura K, et al. Activation of TGFbeta/Smad2 signaling is associated with airway remodeling in asthma. J Allergy Clin Immunol 2002; 110: 249-54

[55] McMillan SJ, Xanthou G, Lloyd CM. Manipulation of allergeninduced airway remodeling by treatment with anti-TGF- $\beta$ antibody: Effect on the Smad signaling pathway. J Immunol 2005; 174 : 5774-80.

[56] Mattoli S, Soloperto M, Marini M, Fasoli A. Levels of endothelin in the bronchoalveolar lavage fluid of patients with symptomatic asthma and reversible airflow obstruction. J Allergy Clin Immunol 1991; 88: 376-84.

[57] Ackerman V, Carpi S, Bellini A, Vassalli G, Marini M, Mattoli S. Constitutive expression of endothelin in bronchial epithelial cells of patients with symptomatic and asymptomatic asthma and modulation by histamine and interleukin-1. J Allergy Clin Immunol 1995; 96: 618-27.

[58] Goldie RG. Potential role of the endothelins in airway remodeling in asthma. Pulm Pharmacol Ther 1999; 12: 79-80.
[59] Pégorier S, Arouche N, Dombret MC, Aubier M, Pretolani M. Augmented epithelial endothelin-1 expression in refractory asthma. J Allergy Clin Immunol 2007; 120: 1301-7.

[60] Schmidt M, Mattoli S. Role in asthmatic lung disease. In: Bucala R, Ed. Fibrocytes: New insights into tissue repair and systemic fibroses. Chapter 6. Singapore: World Scientific Publishing. 2007; pp. 105-23.

[61] Mattoli S. Tissue repair in asthma: The origin of subepithelial fibroblasts and myofibroblasts. In: Chaponnier C, Desmoulière A, Gabbiani G, Eds. Tissue repair, contraction and the myofibroblasts. Chapter 4. Georgetown (TX): Landes Bioscience and Springer Science + Business Media 2006; pp. 40-6.

[62] Marini M, Vittori E, Hollemborg J, Mattoli S. Expression of the potent inflammatory cytokines, granulocyte-macrophage- colonystimulating factor and interleukin-6 and interleukin-8, in bronchial epithelial cells of patients with asthma. J Allergy Clin Immunol 1992; 89: 1001-9.

[63] Nocker RE, Schoonbrood DE, van der Graaf EA, et al. Interleukin8 in airway inflammation in patients with asthma and chronic obstructive pulmonary diseases. Int Arch Allergy Immunol 1996; 109: 183-91.

[64] Hamilton LM, Torres-Lozano C, Puddicombe SM, et al. The role of the epidermal growth factor receptor in sustaining neutrophil inflammation in severe asthma. Clin Exp Allergy 2003; 33: 233-40.

[65] Govindaraju V, Michoud MC, Al-Chalabi M, Ferraro P, Powell WS, Martin JG. Interleukin-8: novel roles in airway smooth muscle contraction and migration. Am J Physiol Cell Physiol 2006; 291: C957-65.

[66] Laan M, Cui ZH, Hoshino $\mathrm{H}$, et al. Neutrophil recruitment by human IL-17 via C-X-C chemokine release in the airways. J Immunol 1999; 162: 2347-52.

[67] Schauer IG, Ressler SJ, Tuxhorn JA, Dang TD, Rowley DR. Elevated epithelial expression of interleukin-8 correlates with myofibroblast reactive stroma in benign prostatic hyperplasia. Urology 2008; 72: 205-13.

[68] Clément S, Pascarella S, Conzelmann S, Gonelle-Gispert C, Guillox K, Negro F. The hepatitis $\mathrm{C}$ virus core protein indirectly induces alpha-smooth muscle actin expression in hepatic stellate cells via interleukin-8. J Hepatol 2010; 52: 635-43.

[69] Feugate JE, Wong L, Li QJ, Martins-Green M. The CXC chemokine cCAF stimulates precocious deposition of ECM molecules by wound fibroblasts, accelerating development of granulation tissue. BMC Cell Biol 2002; 3:13.

[70] Hoshino M, Aoike N, Takahashi M, Nakamura Y, Nakagawa T. Increased immunoreactivity of stroma cell-derived factor-1 and angiogenesis in asthma. Eur Respir J 2003; 21: 804-9.

[71] Negrete-García MC, Velasquez JR, Popoca-Coyotl A, MontesVizuet AR, Juárez-Carvajal E, Teran LM. Chemokine (C-X-C motif) ligand 12/stromal cell-derived factor-1 is associated with leukocyte recruitment in asthma. Chest 2010; 138: 100-6.

[72] Voermans C, Gerritsen WR, von dem Borne AE, van der Schoot CE. Increased migration of cord blood-derived CD34+ cells, as compared to bone marrow and mobilized peripheral blood CD34+ cells, across uncoated or fibronectin-coated filters. Exp Hematol 1999; 27: 1806-14.

[73] Mbemba E, Gluckman JC, Gattegno L. Glycan and glycosaminoglycan binding properties of stromal cell-derived factor (SDF)1alpha. Glycobiology 2000; 10: 21-9.

[74] Pelletier AJ, van der Laan LJ, Hildbrand P, et al. Presentation of chemokine SDF-1 alpha by fibronectrin mediates directed migration of T cells. Blood 2000; 96: 2682-90.

[75] Netelenbos T, Zuijderduijn S, van den Born J, et al. Proteoglycans guide SDF-1-induced migration of hematopoietic progenitor cells. J Leukoc Biol 2002; 72: 353-62.

[76] Phillips RJ, Burdick MD, Hong K, et al. Circulating fibrocytes traffic to the lungs in response to CXCL12 and mediate fibrosis. J Clin Invest 2004; 114: 438-46.

[77] Ziegler SF, Artis D. Sensing the outside world: TSLP regulates barrier immunity. Nat Immunol 2010; 11: 289-93.

[78] Ying S, O’Connor B, Ratoff Q, et al. Thymic stromal lymphopoietin expression is increased in asthmatic airways and correlates 
with expression of Th2-attracting chemokines and disease severity. J Immunol 2005; 174: 8183-90.

[79] Oh M-H, Oh SY, Yu J, et al. IL-13 induces skin fibrosis in atopic dermatitis by thymic stromal lymphopoietin. J Immunol 2011; 186: 7232-42.

[80] Mori L, Bellini A, Stacey MA, Schmidt M, Mattoli S. Fibrocytes contribute to the myofibroblast population in wounded skin and originate from the bone marrow. Exp Cell Res 2005; 304: 81-90.
[81] Wang J, Jiao H, Stewart T, et al. Accelerated wound healing in leukocyte-specific, protein 1-deficient mouse is associated with increased infiltration of leukocytes and fibrocytes. J Leukoc Biol 2007; 82: 1554-63.

[82] Kao H-K, Chen B, Murphy GF, Li Q, Orgill DP, Guo L. Peripheral blood fibrocytes. Enhancement of wound healing by cell proliferation, re-epithelialization, contraction and angiogenesis. Ann Surg 2011; 254: 1066-74.

Received: February 11, 2013

(C) Bellini et al.; Licensee Bentham Open.

This is an open access article licensed under the terms of the Creative Commons Attribution Non-Commercial License (http://creativecommons.org/licenses/ by-nc/3.0/) which permits unrestricted, non-commercial use, distribution and reproduction in any medium, provided the work is properly cited. 